\title{
Exocrine and Endocrine Pancreatic Cancer Pathologic Distant Metastasis TNM Finding v7
}

National Cancer Institute

\section{Source}

National Cancer Institute. Exocrine and Endocrine Pancreatic Cancer Pathologic Distant Metastasis TNM Finding v7. NCI Thesaurus. Code C90299.

A pathologic finding about one or more characteristics of exocrine or endocrine pancreatic cancer, following the rules of the TNM AJCC v7 classification system as they pertain to distant metastases. There is no pathologic Mo for exocrine or endocrine pancreatic cancer. (from AJCC 7th Ed.) 